\title{
Reposisi Pancasila dari Norm Menjadi Values sebagai Integrasi Pancasila dan Islam
}

\author{
Sun Fatayati ${ }^{1}$, Ahmad Gelora Mahardika ${ }^{2 *}$ \\ ${ }^{1}$ Institut Agama Islam Tribakti Kediri, Indonesia \\ ${ }^{2}$ Institut Agama Islam Negeri Tulungagung, Indonesia \\ ${ }^{1}$ sunfatayati13@gmail.com, ${ }^{2}$ geloradika@gmail.com \\ *correspondence author
}

\begin{abstract}
Pancasila and Islam are two ideologies that are often seen as different. This can be seen from the history of the Indonesian state administration where it is recorded that Pancasila was used as a tool for the Government to dissolve organizations and parties with Islamic nuances, namely Masyumi and HTI. The contradiction was caused by the Government placing Pancasila as part of legal norms, not values. Even though the consequence of placing Pancasila as a legal norm should be that there should also be an agency authorized to conduct trials. However, unlike other legal norms, there is no single institution that has the authority to test Pancasila. In addition, according to experts, Pancasila is a building of values which is the way of life of the Indonesian people. The research method in this article is normative juridical. The result states that Pancasila should be positioned as a value, not as a legal norm.
\end{abstract}

Keywords: Integration, Islam, Norm, Pancasila,

\begin{abstract}
Abstrak
Pancasila dan Islam merupakan dua ideologi yang kerap kali dianggap berbeda. Hal itu dapat dilihat dari sejarah ketatanegaraan Indonesia dimana tercatat Pancasila digunakan sebagai alat Pemerintah untuk melakukan pembubaran organisasi dan Partai yang bernuansakan Islam yaitu Masyumi dan HTI. Pertentangan itu disebabkan, Pemerintah menempatkan Pancasila sebagai bagian dari norma hukum bukan nilai. Padahal konsekekuensi penempatan Pancasila sebagai norma hukum selayaknya terdapat pula lembaga yang berwenang melakukan pengujian. Akan tetapi berbeda dengan norma hukum lainnya, tidak terdapat satupun lembaga yang berwenang melakukan pengujian terhadap Pancasila. Selain itu menurut para ahli, Pancasila merupakan bangunan nilai yang menjadi pandangan hidup bangsa Indonesia. Metode penelitian dalam artikel ini adalah yuridis normatif. Hasilnya menyatakan bahwa Pancasila selayakanya diposisikan sebagai nilai, bukan sebagai norma hukum.
\end{abstract}

Kata Kunci: Integrasi, Islam, Norma, Pancasila

\section{Pendahuluan}

Salah satu perdebatan cukup panjang dalam sejarah ketatanegaraan Indonesia adalah penempatan Pancasila sebagai ideologi tunggal bangsa Indonesia. Sebagai Negara dengan mayoritas penduduk beragama Islam, Indonesia selayaknya menempatkan Islam sebagai bagian dari ideologi bangsa. Posisi Pancasila sebagai ideologi tunggal dianggap mempunyai fungsi untuk menyatukan. Hal itu disebabkan, Indonesia mempunyai keragaman dalam berbagai aspek, baik itu suku, budaya, ras, maupun agama. Akan tetapi, penempatan Pancasila sebagai ideologi tunggal kerap menciptakan pertentangan di 
kalangan masyarakat umum. Pertentangan tersebut disebabkan adanya tesis bahwa Islam dan Pancasila merupakan dua ideologi yang terpisah dan tidak dapat diintegrasikan. Padahal, Islam dan Pancasila mempunyai ikatan sejarah yang sangat erat. Sejarah kebangsaan Indonesia mencatat bahwa kemerdekaan Indonesia baik dalam proses perjuangan fisik maupun diplomasi melibatkan Islam di dalamnya. Selain itu, pembahasan naskah asli Pancasila juga didominasi oleh para ahli yang beragama Islam. Oleh karena itu, secara tidak langsung, Islam mempunyai peran dalam memperoleh kemerdekaan Indonesia serta terlibat secara aktif dalam penyusunan teks Pancasila.

Pancasila dan Indonesia mempunyai keterkaitan yang tidak dapat dipisahkan. Kelahiran Pancasila menjadi fundamen dasar munculnya Negara Indonesia. Sejarah mencatat, Pancasila yang diinisasi pertama kali pada tanggal 1 Juni 1945 adalah source of energy, yaitu sebagai kekuatan dan sekaligus sebagai guidelines dalam memperoleh kemerdekaan, menjadi media pemersatu dalam menciptakan kerukunan berbangsa, serta sebagai pandangan hidup atau philosophie grondslag sehari-hari bagi bangsa Indonesia. ${ }^{1}$

Namun, perdebatan yang dilakukan oleh tim sembilan sebagai perumus Pancasila yaitu Soekarno, Moh. Hatta, M. Yamin, A. Maramis, Subardjo, Wachid Hasyim, Kahar Muzakir, Agus Salim dan Abi Kusno Tjokrosuyoso, ${ }^{2}$ ternyata masih menyisakan persoalan yang terus menerus berlanjut hingga sekarang. Persoalan tersebut disebabkan penghapusan tujuh kata dari Piagam Jakarta (The Jakarta Charter) yaitu "dengan kewajiban menjalan syariat Islam bagi pemeluk-pemeluknya". ${ }^{3}$

Penghapusan 7 (tujuh) kata ini mempunyai dampak hingga saat ini. Hal itu disebabkan penghapusan tersebut dianggap sebagai upaya untuk menihilisasi peran Islam dalam proses kemerdekaan Indonesia. Kondisi tersebut diperburuk dengan ketidakstabilan Pemerintahan Indonesia diawal kemerdekaan yang berdampak munculnya gerakan-gerakan separatis dengan simbol-simbol Islam sebagai lokomotifnya antara lain gerakan pemberontakan Darul Islam/Tentara Islam Indonesia (DI/TII) yang terjadi di sejumlah wilayah Indonesia antara lain Jawa Barat, Jawa Tengah, Sulawesi Selatan, Aceh, dan Kalimantan. ${ }^{4}$

\footnotetext{
${ }^{1}$ Ida Bagus Brata and Ida Bagus Nyoman Wartha, "Lahirnya Pancasila Sebagai Pemersatu Bangsa Indonesia,” Jurnal Santiaji Pendidikan 7, no. 1 (2017): 120-32.

2 Agus Fauzi, “Agama, Pancasila Dan Konflik Sosial Di Indonesia," E-Journal Lentera Hukum 4, no. 2 (2017): 122, https://doi.org/10.19184/ejlh.v4i2.5295.

3 Mujar Ibnu Syarif, "Spirit Piagam Jakarta Dalam Undang-Undang Dasar 1945," Jurnal Cita Hukum 4, no. 1 (2016): 15-32.

${ }^{4}$ Nurul Azizah, "Ideologi Gerakan Kahar Mudzakkar Di Sulawesi Selatan 1952-1965," Pemikiran Keislaman 15, no. 2 (2019): 95-104. 
Gerakan perlawanan tersebut menjadi awal dari munculnya persepsi tidak selarasnya antara Pancasila dan Islam. Kondisi tersebut ditandai dengan semakin terpisahnya wilayah Islam dan Pancasila dalam ranah politik, dimulai dari ketidakmampuan Konstituante yang dipilih melalui Pemilu 1955 dalam menyusun UndangUndang Dasar Baru, hingga kemudian identifikasi adanya upaya sekelompok orang dari organisasi Islam untuk menggantikan ideologi Pancasila yang ditandai dengan keluarnya Perpu Nomor 2 Tahun 2017 juncto Undang-Undang Nomor 17 tahun 2013 tentang Organisasi Kemasyarakatan yang kemudian menjadi instrumen hukum untuk mencabut status badan hukum organisasi masyarakat Hizbut Tahrir Indonesia (HTI). Konsepsi yang terbangun cukup lama tersebut pada akhirnya menciptakan identifikasi semu bahwa Pancasila dan Islam merupakan dua ideologi yang berbeda dan tidak sapat disatukan. Padahal sebagai staat fundamental norm, Pancasila merupakan ideologi dasar yang menjadi fundamen terbentuknya Negara serta dasar bagi pembentukan seluruh peraturan perundang-undangan.

Meskipun telah banyak gagasan atau artikel ilmiah yang mengkaji relasi antara Pancasila dan Islam, akan tetapi belum ada artikel yang secara khusus menawarkan reposisi Pancasila dari norm menjadi values. Salah satu artikel yang ditulis oleh Dora Kusumastuti yang berjudul "Developing Subsidized Mortgage Agreement Based on the Justice Values of Pancasila (Indonesian State Philosophy)" dalam Journal of Advanced Research in Law and Economics, Vol. 7, Iss. 8, 2016 menyatakan bahwa Pancasila merupakan sebuah Values yang menjadi petunjuk bagi pengambilan kebijakan Pemerintah terkait ekonomi. Akan tetapi, Dora Kusumastuti tidak mengkaji Pancasila sebagai seperangkat norma yang bersifat mengikat. ${ }^{5}$ Selain itu terdapat pula artikel yang ditulis oleh Rima Yuwana Yustikaningrum yang berjudul "Indonesia and LGBT: Is It Time to Appreciate Local Value?" Yang dimuat dalam Challenges of the Knowledge Society Journal; Bucharest (2018): 712-716. Dalam artikelnya tersebut, Yustikaningrum menggambarkan Pancasila sebagai values dari semua norma yang ada di Indonesia. Menurut Yustikaningrum, selayaknya semua peraturan di Indonesia tunduk pada Pancasila sebagai sumber norma. Penulis dalam artikel tersebut menempatkan norm dan values sebagai esensi tunggal, padahal muara persoalan dimana Pancasila ditempatkan sebagai norma adalah salah problematika yang menciptakan kerancuan hukum.

${ }^{5}$ Dora Kusumastuti, "Developing Subsidized Mortgage Agreement Based on the Justice Values of Pancasila (Indonesian State Philosophy)," Journal of Advanced Research in Law and Economics 7, no. 8 (2016): 2079-85, https://doi.org/10.14505/jarle.v7.8(22).19.

Tribakti: Jurnal Pemikiran Keislaman

Volume 32, Nomor 1, Januari 2021 
Bedasarkan persepsi tersebut, penelitian ini hendak menjawab pertanyaan tentang apakah reposisi pancasila dari norm menjadi values dapat mengintegrasikan pancasila dan Islam?

\section{Metode}

Penelitian ini dilakukan melalui penelitian hukum normatif, yaitu dengan melakukan pengkajian serta analisis terhadap peraturan perundang-undangan atau bahanbahan lain yang berkaitan dengan reposisi pancasila dari norm menjadi values sebagai integrasi pancasila dan Islam. Metode yang dilakukan dalam penelitian ini adalah menggunakan pendekatan peraturan perundang-undangan (statutory approach). ${ }^{6}$ Pendekatan tersebut dilakukan dengan mengkaji sejumlah regulasi terkait dengan tema dalam penelitian ini.

Penelitian hukum normatif yang digunakan dalam penelitian ini menggunakan jenis data kepustakaan, oleh karena itulah metode pengumpulan data dilakukan melalui pencarian literatur yang relevan, baik dengan media perpustakaan ataupun pusat data jurnal yang berbasis daring antara lain dari Proquest, Emerald serta Google Scholar. Pengumpulan data dalam penelitian ini difokuskan pada: (a) bahan hukum primer, berupa peraturan perundang-undangan yang terkait secara langsung dengan tema penelitian; dan (b) bahan hukum sekunder, berupa buku referensi dan jurnal yang terkait dengan tema penelitian dan menguraikan lebih lanjut bahan hukum primer dalam konteks teoretis dan implementasi yang relevan. Bahan hukum primer dan sekunder yang diperoleh akan diinventarisasi dan diidentifikasi untuk selanjutnya dipergunakan untuk menganalisis pokok-pokok permasalahan yang berhubungan dengan kajian penelitian ini dan dilakukan sesuai kebutuhan. Langkah tersebut dapat digunakan sebagai bahan untuk menganalisis pokok-pokok permasalahan. Tahapan berikutnya adalah melakukan analisis bahan hukum yang sudah terkumpulkan sebagai bahan untuk mengkaji tema penelitian.

\section{Hasil dan Pembahasan}

Salah satu kesepakatan monumental yang terjadi dalam sejarah berdirinya bangsa Indonesia adalah Pancasila atau dikenal dengan five principles. Menurut Maroni, Pancasila merupakan the foundation of the state and the live view in the nation and state,

${ }^{6}$ Johni Ibrahim, Teori Dan Metodologi Penelitian Hukum Normatif (Malang: Bayumedia Publishing, 2007): 300 . 
dalam artian Pancasila selain menjadi fondasi berdirinya Negara juga menjadi pandangan hidup bangsa. ${ }^{7}$ Hal itu ditegaskan pula oleh Ambiro yang menyatakan bahwa Pancasila merupakan pedoman dalam kehidupan masyarakat Indonesia dalam menghadapi segala persoalan seiring berkembangnya zaman. ${ }^{8}$ Sebagai pandangan hidup bangsa Indonesia, sebagaimana yang ditujukan dalam ketetapan MPR No. II/MPR/1979, maka Pancasila merupakan jiwa seluruh rakyat Indonesia, pandangan hidup bangsa Indonesia dan dasar Negara Indonesia. Setiap bangsa yang ingin berdiri kokoh dan mengetahui dengan jelas arah serta tujuan yang ingin dicapainya sangat memerlukan nilai-nilai luhur yang dijunjung sebagai pandangan/filsafat hidup. ${ }^{9}$ Terlihat dari sejumlah pendapat tersebut di atas, Pancasila merupakan identitas bangsa Indonesia yang mempunyai keragaman baik suku, agama, ras, maupun golongan.

Namun yang menjadi pertanyaan adalah posisi Islam dalam Pancasila manakala disandingkan dengan kelompok lainnya. Sebagai keyakinan mayoritas masyarakat Indonesia, Islam mempunyai peran sentral dalam proses kemerdekaan baik dalam akar rumput (grassroot) atau melalui para elit politiknya. Peran tersebut dapat dibuktikan dengan melihat sejarah kemerdekaan Indonesia, di mana gerakan-gerakan Islam mempunyai andil besar dalam proses perebutan kekuasaan dari Belanda. ${ }^{10}$ Hipotesis tersebut disepakati oleh Awan yang menyatakan bahwa kelompok Islam terutama Nahdlatul Ulama (NU) dan Muhammadiyah mempunyai peran yang signifikan dalam kemerdekaan, both movements also had inherited the spirit of the socio-religious resistance to colonialism. Thus, their philosophy is that the life under foreign or domestic exploitation is not a life of honor and dignity. And for this reason, the individual and collective freedom is absolutely sacred, and every citizen must fight to achieve it at any cost. ${ }^{11}$ Terlihat dari beberapa pendapat di atas, kemerdekaan Indonesia tidak dapat dipisahkan dari Islam.

\footnotetext{
${ }^{7}$ Maroni, Sopian Sitepu, and Nenny Dwi Ariani, "Humanistic Law Enforcement as the Application of the Value of Justice, Expediency and Legal Certainty Based on Pancasila," Journal of Legal, Ethical and Regulatory Issues 22, no. 4 (2019): 1-6.

${ }^{8}$ Ambiro Puji Asmaroini, "Menjaga Eksistensi Pancasila Dan Penerapannya Bagi Masyarakat Di Era Globalisasi," JPK: Jurnal Pancasila Dan Kewarganegaraan 2, no. 1 (2017): 1-14.

${ }^{9}$ Fransiska Novita Eleanora, "Pancasila Sebagai Norma Dasar Dalam Sistem Hukum Indonesia," ADIL: Jurnal Hukum 3, no. 1 (2019): 141

${ }^{10}$ Beti Yanuri Posha, "Perkembangan Islam Di Indonesia Pasca Kemerdekaan," Historia 3, no. 2 (2015): 75-82.

${ }^{11}$ Muzaffar Awan, “Indonesia's s Democracy and Tolerant Islam,” Defence Journal 17, no. 5 (2010): 23-27,

https://search.proquest.com/docview/1474345645/fulltext/63592A4774714C74PQ/4?accountid=46437. Tribakti: Jurnal Pemikiran Keislaman Volume 32, Nomor 1, Januari 2021
} 
Hubungan yang erat tersebut juga dapat direpresentasikan melalui pembahasan Pancasila yang melibatkan 9 (sembilan) tokoh bangsa dengan mayoritas tokoh tersebut beragama Islam, antara lain dapat dilihat pada tabel berikut ini:

Tabel 1

\section{Agama Panitia Sembilan}

\begin{tabular}{ll}
\hline \multicolumn{1}{c}{ Nama } & Agama \\
\hline Soekarno & Islam \\
Moehammad Hatta & Islam \\
Achmad Soebardjo & Islam \\
Mohammad Yamin & Islam \\
Wahid Hasyim & Islam \\
Abdul Kahar Moezakir & Islam \\
Abikusno Tjokrosoejoso & Islam \\
Agus Salim & Islam \\
A.A Maramis & Kristen \\
\hline
\end{tabular}

Sumber : diolah dari berbagai sumber dengan melakukan pencarian terhadap masingmasing nama melalui situs pencarian daring

Namun, dari kedelapan tokoh yang beragama Islam tersebut pada hakikatnya hanya empat yang mempunyai keterikatan dengan Islam sebagai ideologi, yaitu; Mohammad Yamin, Wahid Hasyim, Andul Kahar Moezakir dan Agus Salim, sementara yang lain, meskipun beragama Islam akan tetapi merupakan kelompok ideologi aliran nasionalis. Menurut Yudi Latif, secara jumlah formasi keanggotan, Panitia Sembilan yang dibentuk untuk menyusun Pancasila mmepunyai komposisi yang lebih tepat dibandingkan Panitia sebelumnya yang didominasi ideologi kebangsaan. Dalam Panitia Sembilan, 5 (lima) orang representasi dari kelompok nasionalis (kebangsaan) serta 4 (empat) orang dari kelompok ideologi Islam berpendapat bahwa kompromi merupakan solusi yang paling tepat dalam mengatasi perbedaan pendapat. Konsensus tersebut pada akhirnya menciptakan perkawinan antara ideologi ketuhanan serta kebangsaan yang direpresentasikan dalam rancangan pembukaan UUD yang oleh Yamin disebut sebagai Piagam Jakarta (Jakarta Charter). ${ }^{12}$

Terlihat berdasarkan tabel 1, pada hakikatnya Pancasila merupakan bentuk kompromi dengan proporsi yang seimbang antara ideologi Islam dan nasionalis. Secara sederhana dapat disimpulkan bahwa Islam mempunyai saham sebesar 50\% (lima puluh persen) dalam pembentukan Pancasila. Oleh karena itulah, tindakan membenturkan Islam dan Pancasila sebagai dua ideologi yang berseberangan pada hakikatnya berpotensi

12 Wildan Sena Utama, "Ulasan Buku Pancasila : Sebuah Monumen Atau Leitstar Dinamis ?," Negara Paripurna: Historisitas, Rasionalitas Dan Aktualitas Pancasila 11, no. 1 (2014). 
menodai Pancasila itu sendiri, dikarenakan Pancasila merupakan hasil kompromistis antara ideologi Islam dan Nasionalis.

Namun muncul pertanyaan besar terkait relasi antara Islam dan Pancasila. Pertanyaan tersebut muncul disebabkan Pancasila mempunyai karakteristik yang cenderung berbeda antara satu pemerintahan dengan pemerintahan lainnya. Pancasila pada era orde lama dimaknai sebagai integrasi ideologi nasionalis, agama dan komunis. ${ }^{13}$ Pada era orde baru dimaknai secara berbeda yaitu identik dengan ekonomi liberal serta indoktrinisasi melalui program Pedoman Penghayatan dan Pengamalan Pancasila (P4). ${ }^{14}$ Sementara itu pada era reformasi di mana terjadi pergantian Presiden secara reguler, Pancasila mengalami pasang surut penafsiran. Hal itu dapat dilihat dengan melihat sikap Pemerintah yang berbeda terkait organisasi yang dianggap bertentangan dengan ideologi Pancasila yaitu Hizbut Tahrir Indonesia (HTI).

\section{Sikap Presiden terhadap Eksistensi HTI}

\begin{tabular}{ccc}
\hline Presiden & Pancasila & Keterangan \\
\hline Habibie & Tidak bertentangan & Terdaftar di Kemendagri \\
Megawati & Tidak bertentangan & Terdaftar di Kemendagri \\
Susilo Bambang & Tidak bertentangan & Terdaftar sebagai Badan Hukum \\
Yudoyono & & Perkumpulan dengan SK Nomor: AHU- \\
& & 00282.60.10.2014 \\
Joko Widodo & Bertentangan & Dicabut dengan Surat Keputusan Nomor \\
& & AHU-30.AH.01.08 tahun 2017
\end{tabular}

Sumber: diolah dari berbagai sumber dengan melakukan analisis terhadap sikap masingmasing Presiden melalui situs pencarian serta situs resmi Direktorat Jenderal Administrasi Hukum Umum untuk mengakses nomor Surat Keputusan yang menjadi dasar pencabutan status badan hukum perkumpulan HTI

Inkonsistensi sikap Pemerintah terhadap Ormas HTI disebabkan tidak ada parameter yang jelas terkait definisi tindakan ataukah sikap yang dianggap bertentangan dengan Pancasila. Padahal sebagai sebuah norma hukum, selayaknya Pancasila mempunyai sifat jelas dan tidak menciptakan ambiguitas (ketidaktentuan). Hal itu ditegaskan oleh Fassi yang menyatakan bahwa "legal ambiguity is a site upon which state

${ }^{13}$ Susanto, "Pancasila Sebagai Identitas Dan Nilai Luhur Bangsa: Analisis Tentang Peran Pancasila Sebagai Modal Sosial Berbangsa Dan Bernegara,” Jurnal Ilmiah Ilmu Pemerintahan 2, no. 1 (2017): 4452, https://doi.org/10.14710/jiip.v2i1.1634.

${ }^{14}$ Yudi Hartono, "Model Pembelajaran Nilai-Nilai Karakter Bangsa Di Indonesia Dari Masa Ke Masa," Agastya: Jurnal Sejarah Dan Pembelajarannya 7, no. 01 (2017): 34-48, https://doi.org/10.25273/ajsp.v7i01.1059.

Tribakti: Jurnal Pemikiran Keislaman

Volume 32, Nomor 1, Januari 2021 
power is located and reinforced in its mutual relation with the law. This notion of legal ambiguity draws upon a nuanced conception that differs from the idea of law as a limit of power and from the idea of law as inherently ambiguous (a property of language). This means that the law is not considered to be a clear boundary that sometimes state officers need to flexibilize to resolve certain unexpected situations ". ${ }^{15}$ Terlihat dari pendapat Fassi tersebut, suatu norma yang kemudian menjadi alat bagi Negara untuk melakukan penegakan hukum selayaknya harus mempunyai parameter yang jelas. Selain mempunyai tafsir yang berbeda-beda di setia rezim pemerintahan, Pancasila juga merupakan satu-satunya norma hukum yang tidak mempunyai lembaga tersendiri yang berwenang menafsirkannya. Hal tersebut berbeda dengan norma hukum lainnya yang terdapat dalam sistem ketatanegaraan Indonesia, antara lain: ${ }^{16}$

Tabel 3

Perbandingan Peraturan dan Kewenangan Penafsirannya

\begin{tabular}{cc}
\hline Pancasila & - \\
\hline UUD 1945 & Mahkamah Konstitusi \\
Undang-Undang & Mahkamah Agung \\
Peraturan Pemerintah Pengganti UU & Mahkamah Agung dan DPR \\
Peraturan Pemerintah & Mahkamah Agung \\
Peraturan Presiden & Mahkamah Agung \\
Peraturan Daerah & Mahkamah Agung \\
\hline
\end{tabular}

Sumber: dengan melakukan pengolahan terhadap pasal 24A dan 24C UUD 1945

Terlihat dari tabel 3 di atas, Pancasila sebagai staat fundamental norm atau norma tertinggi terlihat tidak mempunyai lembaga permanen yang mempunyai kewenangan menafsirkannya. Hal inilah yang kemudian menjadi awal munculnya tafsir tunggal Pancasila bergantung pada rezim yang berkuasa.

\section{Reposisi Pancasila sebagai Nilai Bukan Sebagai Norma}

Salah satu problematika yang kemudian memunculkan kontroversi adalah penggunaan Pancasila sebagai media penegakan hukum yang dilakukan oleh Pemerintah yang sedang berkuasa. Sejarah membuktikan bahwa penegakan hukum yang dilakukan menggunakan Pancasila sebagai medianya kerap kali berdampak negatif terhadap kualitas demokrasi di Indonesia. Sebagai contoh adalah pembubaran Masyumi yang

\footnotetext{
${ }^{15}$ Marisa Fassi, "Legal Ambiguity As A Site Of Power And Resistance: Sex Work And The Police In Córdoba-Argentina," Zhurnal Issledovanii Sotsialnoi Politiki = The Journal of Social Policy Studies 12, no. 2 (2014): 275-86.

16 Ahmad Gelora Mahardika, "Menggali Nilai-Nilai Kebangsaan Dalam Pancasila Sebagai Groundnorm Negara Kesatuan Republik Indonesia,” Ahkam 6, no. 2 (2018): 267-92.
} 
dilakukan oleh Presiden Soekarno pada tahun 1960 dikarenakan alasan ideologi Masyumi bertentangan dengan Pancasila. ${ }^{17} \mathrm{Hal}$ itu juga berlanjut dengan tindakan-tindakan represif orde baru seperti larangan kritik media, demonstrasi serta diskusi-diskusi kritis yang dianggap tidak sejalan dengan Pancasila. ${ }^{18}$

Oleh karena itulah penggunaan Pancasila untuk kedepannya selayaknya tidak lagi digunakan sebagai instrumen hukum, melainkan sebagai instrumen nilai yang hidup dan berkembang di masyarakat. Hal tersebut didasarkan pada sejumlah pendapat ahli terkait Pancasila, menurut Yustikaningrum "Pancasila is a crystallization form of the values such as religious, social, and cultural realm which live within Indonesian society". ${ }^{19}$ Sebagai sebuah nilai, merujuk pada pendapat Notonagoro ada tiga macam inti dari suatu nilai antara lain: (1) material; (2) vital; (3) spirituality. Something said to be of material value if it is useful for the human body, while it is vital if it is useful for humans to do activities. If you pay attention to the material value and vital value is almost the same as the instrumental value of Louis O. Kattsoff. Spiritual values are distinguished from: (a) truth or reality values, which are based on human reason (ratio) elements; $(b)$ beauty values, which come from human aesthetic elements; (c) values of moral goodness, which are based on human will (karsa); and (d) religious value, which is rooted in human belief, accompanied by appreciation through reason and conscience. ${ }^{20}$

Berdasarkan pendapat Yustikaningrum dan Notonagoro di atas, dapatlah dipahami bahwa Pancasila mempunyai kedekatan secara materil sebagai nilai dibandingkan sebagai media penegakan hukum. Oleh karena itulah untuk melihat apakah Pancasila bertentangan dengan Islam atau tidak, maka hal tersebut bisa dilihat dengan menyandingkan antara nilai-nilai Islam dengan nilai Pancasila.

\section{Nilai-Nilai Islam dalam Pancasila}

Pancasila adalah bangunan nilai yang menjadi pandangan hidup bangsa Indonesia. Ketika memposisikan Pancasila sebagai nilai (values), maka untuk mengetahui apakah

\footnotetext{
${ }^{17}$ Sapti Eka Pratiwi, "Pembubaran Partai Politik Di Indonesia Pada Masa Demokrasi Terpimpin," Avatara 4, no. 3 (2016): 1059-70.

18 Andi Suwirta, "Pers Dan Kritik Sosial Pada Masa Orde Baru: Studi Kasus Pers Mingguan Mahasiswa Indonesia Di Bandung, 1966-1974," Mimbar Pendidikan 3, no. 2 (2018): 113-36, https://doi.org/10.17509/mimbardik.v3i2.13949.

${ }^{19}$ Rima Yuwana Yustikaningrum, "Indonesia and LGBT: Is It Time to Appreciate Local Value ?," Challenges of the Knowledge Society. Public Law, n.d., 712-16.

${ }^{20}$ Parningotan Malau and Alvi Syahrin, "An Obligation of Corporate Criminal Liability in the Case of Non-Implementation of Occupational Health and Safety (OHS)," Journal of Advanced Research in Law and Economics 11, no. 1 (2020): 121-35, https://doi.org/10.14505/jarle.v11.1(47).16.

Tribakti: Jurnal Pemikiran Keislaman

Volume 32, Nomor 1, Januari 2021
} 
Islam telah terintegrasi dengan Pancasila dapat dilakukan dengan melihat keberadaan nilai-nilai Islam dalam Pancasila.

Mengacu pada pendapat Hamka Haq, pada hakikatnya nilai Islam telah terdapat pada setiap Sila dalam Pancasila. Hamka Haq melakukan analisis terhadap setiap sila dalam Pancasila, antara lain: ${ }^{21}$

\section{Sila Pertama, Ketuhanan Yang Maha Esa}

Keberadaan Sila Pertama menjadi salah satu perdebatan, hal itu dikarenakan Soekarno pada awalnya menempatkan ketuhanan berada di paling akhir. ${ }^{22}$ Keharmonisan frase "ketuhanan" dengan Islam dapat diamati dalam kitab suci al-Qur'an yang mana selalu menempatkan Tuhan dalam posisi yang tunggal, konsep tersebut terdapat dalam Surat al-Baqarah ayat 163 yang terjemahannya sebagai berikut; "Dan Tuhan kamu itu adalah Tuhan Yang Maha Esa. Tidak ada Tuhan melainkan Dia Yang Maha Murah, lagi Maha Penyayang". Hipotesis tersebut menggambarkan bahwa fundamen bernegara masyarakat Indonesia adalah penempatan Tuhan sebagai fondasi dasar. Dalam agama Islam, konsep relasi antara Tuhan dan manusia disebut hablum min Allah.

\section{Sila Kedua, Kemanusiaan yang Adil dan Beradab}

Berbeda dengan sila pertama, sila kedua memberikan gambaran bahwa bangsa Indonesia menempatkan hak individual sebagai hak yang yang harus dijunjung, dihormati dan dihargai. Apabila relasi manusia dengan Tuhan direpresentasikan melalui sila pertama, maka relasi antara manusia satu dengan yang lain diwujudkan melalui sila kedua. Sketsa Hablum min an-nass (hubungan sesama manusia) diwujudkan dalam bentuk saling menghormati sesama manusia. Selain itu konsep "adil” dalam sila kedua mempunyai makna bahwa segala tindakan hukum harus didasarkan pada prinsip persamaan, dalam artian tidak boleh ada tindakan diskriminatif dikarenakan semua manusia sama di depan Sang Pencipta. Prinsip keadilan juga tercantum dalam al-Qur'an yaitu surat al-Maa'idah, ayat 8 yang artinya sebagai berikut: "Hai orang-orang yang beriman hendaklah kamu jadi orang-orang yang selalu menegakkan (kebenaran). Karena Allah, menjadi saksi dengan adil dan janganlah sekali-kali kebencianmu

${ }^{21}$ M Saifullah Rohman, "Kandungan Nilai-Nilai Syariat Islam Dalam Pancasila," Jurnal Studi Agama Millah 13, no. 1 (2013): 205-15, http://www.nu.or.id/a,public-m,dinamic-s,detail-ids,4-id,40159lang,id-c,kolom-t,Pancasi.

22 Aris Hardinanto, "Untuk Menyelidiki Usaha-Usaha Persiapan Kemerdekaan Diterjemahkan Sebagai Badan Penyelidik Usaha Persiapan Kemerdekaan,” Veritas 3, no. 1 (1945): 43-64. 
terhadap sesuatu kaum, mendorong kamu untuk berlaku tidak adil. Berlaku adillah, karena adil itu lebih dekat kepada takwa dan bertakwalah kepada Allah, Sesungguhnya Allah Maha mengetahui apa yang kamu kerjakan." (QS. al-Maa'idah [5]: 8).

\section{Sila Ketiga, Persatuan Indonesia}

Sebagai Negara kepulauan dengan beragama suku, budaya, ras, dan agama, konsep kesatuan menjadi sesuatu hal yang vital bagi bangsa Indonesa. Persatuan dalam konsep NKRI tidak hanya persatuan secara geografis wilayah, melainkan juga persatuan secara kebangsaan. Apabila mengacu pada filosofi ajaran Islam, terdapat konsep Ukhuwah Islamiyah (persatuan sesama pemeluk agama Islam) serta Ukhuwah Insaniyah (persatuan sesama manusia tanpa membedakan agama). Pada hakikatnya, kedua konsep tersebut tidak saling bertentangan satu sama lain, hal itu dapat dibuktikan dengan mengacu pada al-Qur'an; “Dan berpeganglah kamu semuanya kepada tali (agama) Allah, dan janganlah kamu bercerai berai, dan ingatlah akan nikmat Allah kepadamu ketika kamu dahulu (masa Jahiliyah) bermusuh-musuhan, Maka Allah mempersatukan hatimu, lalu menjadilah kamu Karena nikmat Allah, orang-orang yang bersaudara; dan kamu telah berada di tepi jurang neraka, lalu Allah menyelamatkan kamu dari padanya. Demikianlah Allah menerangkan ayat-ayat-Nya kepadamu, agar kamu mendapat petunjuk." (Q.S. Ali Imran [3]: 103). “Orang-orang beriman itu sesungguhnya bersaudara. Sebab itu, damaikanlah (perbaikilah hubungan) antara kedua saudaramu itu dan takutlah terhadap Allah, supaya kamu mendapat rahmat." (Q.S. al-Hujurat [49]: $10)$.

\section{Sila Keempat, Kerakyatan yang Dipimpin oleh Hikmat Kebijaksanaan dalam Permusyawaratan dan Perwakilan}

Pengambilan keputusan secara musywarah pada hakikatnya merupakan salah satu ciri khas bangsa Indonesia yang membedakan dengan Negara demokrasi lainnya. Pengambilan keputusan dengan musyawarah (deliberation) memberikan kepastian bahwa tidak ada pihak yang menang dan kalah, hal itu berbeda dengan konsep pengambilan keputusan dengan suara terbanyak (voting). Konsep musyawarah dalam pengambila keputusan dapat ditemukan dalam al-Qur'an, salah satunya dalam Surat Ali Imron, ayat 159:

"Maka disebabkan rahmat dari Allah-lah kamu berlaku lemah lembut terhadap mereka. sekiranya kamu bersikap keras lagi berhati kasar, tentulah mereka menjauhkan diri dari sekelilingmu. Karena itu ma'afkanlah mereka, 
mohonkanlah ampun bagi mereka, dan bermusyawarahlah dengan mereka dalam urusan itu. Kemudian apabila kamu tlah membulatkan tekad, Maka bertawakkallah kepada Allah. Sesungguhnya, Allah menyukai orang-orang yang bertawakkal kepada-Nya." (QS. Ali Imron [3]: 159). "Dan (bagi) orangorang yang menerima (mematuhi) seruan Tuhannya dan mendirikan shalat, sedang urusan mereka (diputuskan) dengan musyawarah antara mereka; dan mereka menafkahkan sebagian dari rezki yang kami berikan kepada mereka." (QS. asySyuura [42]: 38).

\section{Sila Kelima, Keadilan Bagi Seluruh Rakyat Indonesia}

Berbeda dengan sila-sila sebelumnya, sila kelima merupakan refleksi dari pengambilan keputusan yang dilakukan oleh Negara. Berdasarkan sila kelima, Negara selayaknya menempatkan keadilan sebagai supremasi dalam pengambilan keputusan, proses kebijakan harus mengesampingkan kepentingan pribadi ataupun golongan. Mengenai konsep keadilan dalam Islam dapat diamati pada beberapa surat dalam alQur'an, antara lain: “Sesungguhnya Allah menyuruh (kamu) berlaku adil dan berbuat kebajikan, memberi kepada kaum kerabat, dan Allah melarang dari perbuatan keji, kemungkaran dan permusuhan. dia memberi pengajaran kepadamu agar kamu dapat mengambil pelajaran." (Q.S. anNahl [16]: 90)

Selain analisis yang disampaikan oleh Hamka Haq diatas, keterkaitan antara Islam dan Pancasila sebagai nilai disepakati pula oleh sejumlah ahli, antara lain Irsyadillah yang melihat Pancasila dan Islam adalah nilai luhur yang membangun etika dan moral bangsa Indonesia, "indigenous moral and ethical values coming from Islam and Pancasila". ${ }^{23}$ Tidak adanya pertentangan antara Pancasila dan Islam juga disepakati oleh Natsir, yang menyatakan bahwa Pancasila is a foundation that is not at all contrary to the Qur'an. Even Pancasila is the values that will flourish on the foundation of Islam. It does not contradict the everlasting God's revelation. However, Islam provides with great standards based on the Qur'an and al-Sunnah. None of the precepts listed in Pancasila are contradictory and intersect with Islam. ${ }^{24}$

Berdasarkan pendapat Natsir tersebut diatas, terlihat jelas bahwa nilai-nilai Pancasila dan Islam pada hakikatnya tidak ada yang bertentangan satu sama lian.

${ }^{23}$ Irsyadillah Irsyadillah and Alhashmi Aboubaker Lasyoud, "Does Accounting Education Develop Ethical Maturity? Evidence from Indonesia," Journal of Accounting and Management Information Systems 17, no. 3 (2018): 462-83, https://doi.org/10.24818/jamis.2018.03007.

24 Ris'an Rusli, "The State Concept: The Political Thinking of Mohammad Natsir," International Journal of Islamic Thought 13, no. 1 (2018): 105-18, https://doi.org/10.24035/ijit.06.2018.010. 
Salah satu problematika dalam sejarah ketatanegaraan Indonesia adalah konflik ideologi yang kerap kali menempatkan Pancasila dan Islam dalam dua sudut ring yang terpisah. Hal itulah yang kemudian memunculkan persepsi publik bahwa antara Pancasila dan Islam merupakan dua ideologi yang berbeda. Kondisi itu disebabkan, Pemerintah menempatkan Pancasila sebagai bagian dari norma hukum. Hipotesis tersebut didasarkan pada fakta empiris di mana dalam sejarah kebangsaan, Pancasila kerap kali digunakan sebagai alat penguasa untuk melakukan penegakan hukum. Hal itu sudah terjadi sejak era Presiden Soekarno, Presiden Soeharto dan Presiden Joko Widodo.

Memposisikan Pancasila sebagai norma hukum, secara normatif akan menciptakan kompleksitas terkait parameter atau indikatornya. Hal itu disebabkan, berbeda dengan norma hukum lainnya yaitu UUD NRI 1945, UU/Perpu, PP, Perpres dan Peratura Daerah, kesemua norma hukum tersebut secara jelas diatur terkait lembaga mana yang berwenangan melakukan pengujian, hal tersebut berbeda dengan Pancasila yang dalam sistem hukum Indonesa tidak diatur kewenangan tersebut. Kondisi itulah yang kemudian kerap kali menciptakan pertentangan antara Pancasila dan Islam. Padahal, sejumlah ahli menyatakan bahwa Pancasila bukanlah bangunan norma melainkan bangunan nilai. Oleh karena itulah, Pancasila selayaknya tidak diposisikan sebagai norma hukum melainkan sebagai nilai yang tumbuh dalam diri bangsa Indonesia.

\section{Kesimpulan}

Manakala menempatkan Pancasila sebagai nilai, pada hakikatnya terdapat ketersinggungan antara Islam dan Pancasila. Hal itu telah disepakati pula oleh Hamka Haq dan Natsir. Berdasarkan hal tersebut itulah, selayaknya kedepannya Pemerintah menempatkan Pancasila sebagai nilai bukan sebagai norma untuk menghindari adanya tindakan Pemerintah yang justru kontradiktif dengan semangat Pancasila.

Implikasi dari penelitian ini adalah apabila Pancasila ditempatkan sebagai bangunan nilai (values) maka Pancasila tidak akan diposisikan lagi sebagai norma yang mana dapat menjadi media penegakan hukum. Pancasila selayaknya cukup menjadi panduan hidup setiap insan bernegara, bukan sebagai norma yang mempunyai kekuatan mengikat yang berpotensi untuk disalahgunakan oleh penguasa. 


\section{Daftar Pustaka}

Asmaroini, Ambiro Puji. "Menjaga Eksistensi Pancasila Dan Penerapannya Bagi Masyarakat Di Era Globalisasi." JPK: Jurnal Pancasila Dan Kewarganegaraan 2, no. 1 (2017): 1-14.

Awan, Muzaffar. “Indonesia' s Democracy and Tolerant Islam.” Defence Journal 17, no. 5 (2010):

23-27. https://search.proquest.com/docview/1474345645/fulltext/63592A4774714C74PQ/ 4? accountid $=46437$.

Azizah, Nurul. "Ideologi Gerakan Kahar Mudzakkar Di Sulawesi Selatan 1952-1965." Pemikiran Keislaman 15, no. 2 (2019): 95-104.

Brata, Ida Bagus, and Ida Bagus Nyoman Wartha. "Lahirnya Pancasila Sebagai Pemersatu Bangsa Indonesia.” Jurnal Santiaji Pendidikan 7, no. 1 (2017): 120-32.

Fassi, Marisa. "Legal Ambiguity As A Site Of Power And Resistance: Sex Work And The Police In Córdoba-Argentina." Zhurnal Issledovanii Sotsialnoi Politiki $=$ The Journal of Social Policy Studies 12, no. 2 (2014): 275-86.

Fauzi, Agus. "Agama, Pancasila Dan Konflik Sosial Di Indonesia.” E-Journal Lentera Hukum 4, no. 2 (2017): 122. https://doi.org/10.19184/ejlh.v4i2.5295.

Hardinanto, Aris. "Untuk Menyelidiki Usaha-Usaha Persiapan Kemerdekaan Diterjemahkan Sebagai Badan Penyelidik Usaha Persiapan Kemerdekaan.” Veritas 3, no. 1 (1945): 43-64.

Hartono, Yudi. "Model Pembelajaran Nilai-Nilai Karakter Bangsa Di Indonesia Dari Masa Ke Masa.” Agastya: Jurnal Sejarah Dan Pembelajarannya 7, no. 01 (2017): 34-48. https://doi.org/10.25273/ajsp.v7i01.1059.

Ibrahim, Johni. Teori Dan Metodologi Penelitian Hukum Normatif. Malang: Bayumedia Publishing, 2007.

Irsyadillah, Irsyadillah, and Alhashmi Aboubaker Lasyoud. "Does Accounting Education Develop Ethical Maturity? Evidence from Indonesia." Journal of Accounting and Management Information Systems 17, no. 3 (2018): 462-83. https://doi.org/10.24818/jamis.2018.03007.

Kusumastuti, Dora. "Developing Subsidized Mortgage Agreement Based on the Justice Values of Pancasila (Indonesian State Philosophy)." Journal of Advanced Research in Law and Economics 7, no. 8 (2016): 2079-85. https://doi.org/10.14505/jarle.v7.8(22).19.

Mahardika, Ahmad Gelora. "Menggali Nilai-Nilai Kebangsaan Dalam Pancasila Sebagai Groundnorm Negara Kesatuan Republik Indonesia." Ahkam 6, no. 2 (2018): 26792.

Malau, Parningotan, and Alvi Syahrin. "An Obligation of Corporate Criminal Liability in the Case of Non-Implementation of Occupational Health and Safety (OHS)." Journal of Advanced Research in Law and Economics 11, no. 1 (2020): 121-35. https://doi.org/10.14505/jarle.v11.1(47).16.

Maroni, Sopian Sitepu, and Nenny Dwi Ariani. "Humanistic Law Enforcement as the Application of the Value of Justice, Expediency and Legal Certainty Based on 
Pancasila.” Journal of Legal, Ethical and Regulatory Issues 22, no. 4 (2019): 1-6.

Novita Eleanora, Fransiska. "Pancasila Sebagai Norma Dasar Dalam Sistem Hukum Indonesia." ADIL: Jurnal Hukum 3, no. 1 (2019): 141. https://doi.org/10.33476/ajl.v3i1.838.

Posha, Beti Yanuri. "Perkembangan Islam Di Indonesia Pasca Kemerdekaan." Historia 3, no. 2 (2015): 75-82.

Pratiwi, Sapti Eka. "Pembubaran Partai Politik Di Indonesia Pada Masa Demokrasi Terpimpin." Avatara 4, no. 3 (2016): 1059-70.

Rohman, M Saifullah. "Kandungan Nilai-Nilai Syariat Islam Dalam Pancasila.” Jurnal Studi Agama Millah 13, no. 1 (2013): 205-15. http://www.nu.or.id/a,publicm,dinamic-s,detail-ids,4-id,40159-lang,id-c,kolom-t,Pancasi.

Rusli, Ris'an. "The State Concept: The Political Thinking of Mohammad Natsir." International Journal of Islamic Thought 13, no. 1 (2018): 105-18. https://doi.org/10.24035/ijit.06.2018.010.

Susanto. "Pancasila Sebagai Identitas Dan Nilai Luhur Bangsa: Analisis Tentang Peran Pancasila Sebagai Modal Sosial Berbangsa Dan Bernegara." Jurnal Ilmiah Ilmu Pemerintahan 2, no. 1 (2017): 44-52. https://doi.org/10.14710/jiip.v2i1.1634.

Suwirta, Andi. "Pers Dan Kritik Sosial Pada Masa Orde Baru: Studi Kasus Pers Mingguan Mahasiswa Indonesia Di Bandung, 1966-1974." Mimbar Pendidikan 3, no. 2 (2018): 113-36. https://doi.org/10.17509/mimbardik.v3i2.13949.

Syarif, Mujar Ibnu. "Spirit Piagam Jakarta Dalam Undang-Undang Dasar 1945.” Jurnal Cita Hukum 4, no. 1 (2016): 15-32. https://doi.org/10.15408/jch.v4i1.3568.

Utama, Wildan Sena. "Ulasan Buku Pancasila: Sebuah Monumen Atau Leitstar Dinamis ?" Negara Paripurna: Historisitas, Rasionalitas Dan Aktualitas Pancasila 11, no. 1 (2014).

Yustikaningrum, Rima Yuwana. "Indonesia and LGBT: Is It Time to Appreciate Local Value?" Challenges of the Knowledge Society. Public Law, n.d., 712-16. 


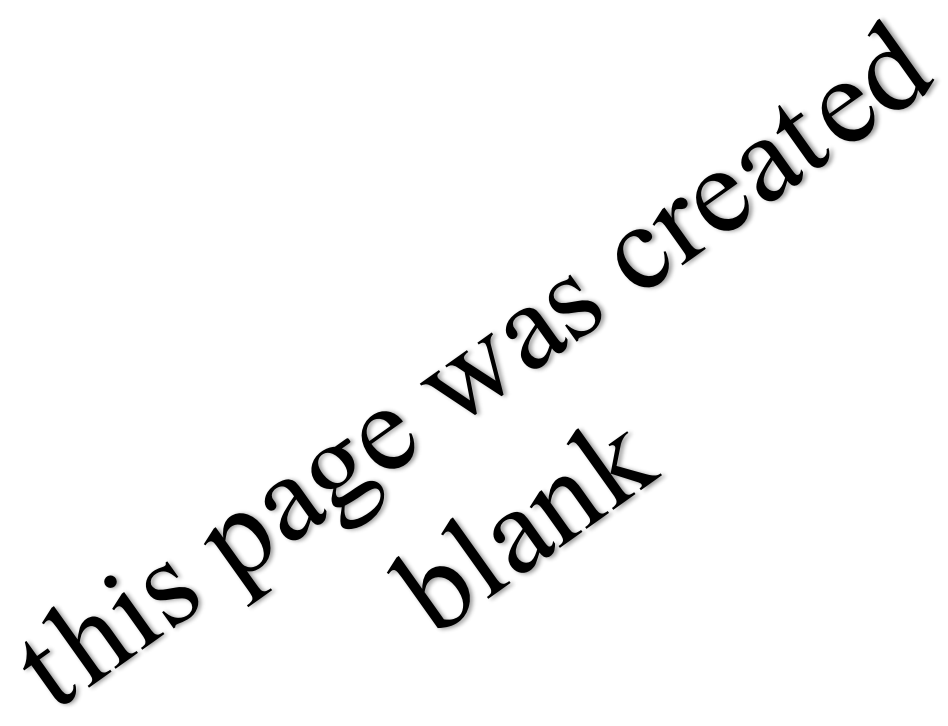

